\title{
Escenario discursivo y significados implícitos en una guía 'para los verdaderos viajeros': el caso de la Guía Azul de Zaragoza
}

\author{
Giovanni Garofalo ${ }^{i}$
}

Università di Bergamo (Italia)

\begin{abstract}
Resumen: El presente estudio se centra en las estrategias manipulatorias empleadas en la 'construcción' del destino turístico, poniendo en evidencia la evolución de algunos mitos señalados por Barthes (catolicismo, pasado imperial, concepto de 'nación española'). En efecto, en algunas guías más recientes se vislumbra la afirmación de una nueva mitología, en la que ocupa un lugar privilegiado el particularismo local y el anhelo de autogobierno. Como muestra de este enfoque crítico, se describen los procedimientos discursivos de la Guía Azul de Zaragoza. Tras esbozar la 'escenografía' o modelo de representación, el análisis propuesto apunta a demostrar que la imagen del lugar y la memoria discursiva se reflejan en el texto mediante significados implícitos como las presuposiciones y la ironía.
\end{abstract}

Palabras clave: guías turísticas, análisis crítico de género, ideología, identidades discursivas, presuposiciones, ironía

Title: Discursive scenery and implicit meanings in a tourist guide for 'die-hard travellers': the case of the Spanish Blue Guide of Zaragoza

Abstract: This study focuses on the manipulation strategies used in the 'construction' of the tourist destination, emphasizing the evolution of some myths indicated by Barthes (catholicism, the imperial past, the concept of 'Spanish nation'). Actually, some recent guides hint at the rising of a fresh mythology in which local particularism and the century-old desire for self-governance plays an essential role. After outlining the 'scenography' or representation model, the suggested analysis aims to prove that both the image of the place and the discursive memory are reflected in the text through implicit meaning, such as presupposition and irony.

Keywords: travel guides, critical genre analysis, ideology, discursive identities, presuppositions, irony

i E-mail:giovanni.garofalo@unibg.it 


\section{Introducción}

A mediados del siglo pasado, Barthes (1957 / 1999) publicó un breve ensayo sobre la Guía Azul, en el cual desenmascaraba las mitologías burguesas que subyacen en la descripción de los destinos turísticos. Dicho estudio, que se convertiría en piedra de toque para la investigación posterior, dedicaba un amplio espacio a las mistificaciones de los atractivos turísticos de España, donde el paisaje solo existe bajo sus connotaciones más pintorescas, que salen a relucir "cada vez que el suelo aparece accidentado" (Barthes, 1957 / 1999: 68). El resultado de este afán deformador de la realidad española es la total ausencia del elemento humano, que desaparece en provecho exclusivo de los monumentos. En las páginas de la Guía Azul todo el país, en opinión de Barthes, no es nada más que una colección de edificios religiosos, que exaltan el papel primario que la ideología burguesa atribuye al cristianismo como elemento constitutivo de la 'identidad española' y motor de la economía turística, ya que "desde el punto de vista burgués resulta poco menos que imposible imaginar una historia del arte que no sea cristiana y católica" y "solo se viaja para visitar iglesias" (Barthes, 1957 / 1999: 69). Así pues, la omisión del presente, de la vida cotidiana y de la geografía humana del país hacen que el monumento se vuelva opaco, indescifrable y hasta estúpido. Como consecuencia de este proceso de mistificación, la guía acaba traicionando su función - sintetizada por Moirand (2004) en la fórmula "dar a conocer, hacer ver, decir cómo hacer" - y se convierte en un medio de ofuscamiento del destinatario.

En el presente trabajo se procura averiguar en qué dirección han evolucionado dichos mitos en el proceso de creación de la identidad del destino turístico, presuponiendo que el texto no es únicamente un conjunto de signos (o elementos significantes que remiten a contenidos o representaciones), sino que constituye más bien una práctica que plasma sistemáticamente los objetos de los que habla (Foucault, 1969: 66; Fairclough, 1995: 22-28). Esta noción de texto como proceso dirigido a la producción de sentido, pone de manifiesto el íntimo nexo entre la lengua y la ideología del emisor, que se concretiza en la guía determinando la imagen del lugar. La crítica realizada por Barthes se refería a la visión de la España franquista de los años cincuenta del pasado siglo: la evolución sociopolítica de los últimos sesenta años ha producido en las guías contemporáneas nuevas representaciones de la realidad española, basadas en manipulaciones y marcos discursivos de otro tipo. En los siguientes epígrafes se observará, en concreto, la transformación de algunos mitos burgueses - principalmente la tradición cristiana, la nobleza de los progenitores de la nación española y la visión unitaria de España - y la aparición de un nuevo repertorio mitológico, tal como este se refleja en la Guía Azul de Zaragoza (en lo sucesivo la GAZ), publicada en 2008-09 por la editorial Gaesa. Como se apreciará, en la modelización de la ciudad y de sus alrededores intervienen de manera determinante algunas formas de la comu- nicación implícita (Sbisà, 2007), como las presuposiciones informativas o la ironía verbal, que añaden información a los marcos prediscursivos colectivos (conocimientos enciclopédicos, creencias, emociones, percepciones) que comparten el emisor y el destinatario, transmitidos sincrónica y diacrónicamente y que se han dado en llamar 'memoria discursiva' (Paveau, 2005; Antelmi, 2011). De manera preliminar, será oportuno detenerse en los rasgos caracterizadores de la guía y en el posicionamiento del enunciador y del destinatario, a saber, en la 'escenografía' y en el ethos discursivo del autor (Antelmi, 2010).

\section{Características de la GAZ, escenografía y ethos di- scursivo}

Por su variedad de secuencias textuales descriptivas, narrativas y prescriptivas y por su mezcla de elementos procedentes de múltiples sectores especializados como son la historia, la historia del arte, la geografía, la economía o la gastronomía, la GAZ se configura como un macrogénero (Calvi, 2011: 21), resultado de la combinación de variedades textuales dotadas de un formato independiente. Consideradas aisladamente, algunas secciones que componen la guía podrían configurar, de hecho, auténticos géneros autónomos:

1. Una breve introducción;

2. Una sección denominada Antes del viaje, que recoge información práctica sobre los medios de transporte que llegan a Zaragoza, destinada a los viajeros que deseen planear con antelación su desplazamiento;

3. Una sección dedicada a la Información general, que presenta el formato de un ensayo e incluye un esbozo histórico-geográfico de la zona, con referencias esenciales a la cultura, a la lengua y a la gastronomía aragonesa;

4. Un apartado titulado Zaragoza imprescindible, asimilable a una breve folleto que, siguiendo el criterio de la economía en la planificación del viaje, se reduce a un listado comentado de los ocho monumentos más célebres de la ciudad, al cual se añaden elementos gráficos. Así pues, la GAZ procura optimizar la estancia del potencial viajero, para que este pueda sacar el mayor provecho del tiempo que pase en la ciudad;

5. Una sección consagrada a la visita de la capital maña, que en su parte inicial ofrece un mapa de la ciudad de fácil consulta, adscribible al género itinerario. Se trata de la parte más descriptiva, en la que el orden de presentación de los lugares no sigue un criterio alfabético sino topográfico: el punto de partida es la Plaza del Pilar, el corazón palpitante de la ciudad con su Basílica, y a continuación se reseñan los demás monumentos, en rutas alternativas que se despliegan alrededor de ese núcleo;

6. Unos apartados que facilitan información útil durante el viaje (transportes, alojamiento, tapas, copas, compras, cultura, ocio y espectáculos, fiestas y festivales) que, junto con la información que se proporciona en el apartado 1, podría configurarse como una breve guía 
práctica;

7. Una sección dedicada a los alrededores de Zaragoza, subdividida en seis itinerarios principales (Comarca de las cinco villas, Ribera baja del Ebro o Ruta de Caspe, La tierra del vino o ruta de Goya, Ruta del río Jalón o ruta de Calatayud, La ruta del Cid, Ruta del Moncayo);

8. Un apartado final sobre la Expo de Zaragoza 2008, temporalmente relevante en la edición de la guía objeto de este estudio.

La organización tipográfica (uso del subrayado y de la negrita para señalar los lugares más interesantes) y la riqueza de ilustraciones facilitan la percepción y la descodificación del texto por parte del lector, quien se acostumbra rápidamente a identificar los caracteres que señalan los lugares más relevantes, o a seguir las remisiones internas a la guía cuando desee profundizar en algún aspecto de su visita. Dicha codificación de los rasgos tipográficos, por tanto, otorga ribetes de multimodalidad al texto impreso e influye eficazmente en la elaboración del mensaje por parte del destinatario (Santulli 2009a: 99-100).

Pese a la identidad del nombre comercial, la Guía Azul española se parece poco a su homóloga francesa (Guide $B l e u$ ), que goza de un afianzado prestigio internacional y se caracteriza como 'guía seria', aledaña a los relatos de viaje y destinada a un público culto, amante de la literatura y de las bellas artes y no desprovisto de cierto gusto por la erudición (Margarito, 2000: 12). Como sus propios editores admiten, la Guía Azul pretende ser en cambio una guía 'turístico-práctica', una variedad híbrida y original, de producción netamente española ${ }^{1}$ :

(1) GUÍAS AZULES es la editorial que lleva más años en el mercado publicando guías turístico-prácticas de producción propia en español [...]. La comercialización de nuestras guías corre a cargo de COMERCIAL GRUPO ANAYA, la mayor y más moderna organización de distribución del sector editorial español, lo que permite que nuestras guías se puedan adquirir en infinidad de puntos de venta, librerías y grandes superficies de España. También se pueden adquirir en algunas librerías de Hispanoamérica y Europa (http://www.guiazuldeltrotamundos.es/empresa.asp).

Así pues, la Guía Azul se instala en la senda de la prestigiosa tradición francesa de la Guide Bleu (de hecho, la editorial Gaesa pertenece al grupo Anaya S.A., integrado desde 2004 en el grupo Hachette Livre ${ }^{2}$ ), aunque asume el tono discursivo de la Guide du Routard o de la Guía del Trotamundos ${ }^{3}$, como indican claramente las coletillas que se añaden a su nombre comercial "el mundo a tu aire" y "las mejores guías para los verdaderos viajeros". Como es sabido, esta última variedad de guía turística se dirige al viajero y no al turista ${ }^{4}$, principalmente a un público joven, capaz de arreglárselas en un país extranjero, encontrando soluciones baratas y desplazándose con el mínimo equipaje indispensable. Asimismo, se trata de una guía que otorga importancia al contacto con los lugareños y a la cultura del país (Margarito, 2000: 16) y que renuncia a menudo a la fría impersonalidad, recurriendo con frecuencia a un registro coloquial y a un tono chistoso (Antelmi, 2010: 38), sobre todo cuando se trata de amenizar la narración de los avatares históricos, adecuando el texto al gusto y al horizonte de espera de esta tipología de destinatario. Obsérvese, por ejemplo, el recurso a los verbos zumbar y enchufar, diafásicamente marcados como informales:

(2) [La caída del imperio romano] El cristianismo es ya la religión oficial de un Imperio que se encuentra en franca decadencia [...] acosado por la presión fronteriza de los pueblos bárbaros - les urgía una salida hacia Occidente porque los hunos les zumbaban por la retaguardia - y las disputas intestinas [...] (GAZ, 32).

(3) [Francisco Goya] Una vez casado con la hermana de Francisco Bayeu, renombrado pintor de corte, su cuñado lo enchufa en la Real Fábrica de Tapices (1775) [...] (GAZ, 55).

Estas elecciones lingüísticas revelan el tipo de 'escenografía ${ }^{5}$ ' o situación que el texto pretende poner en escena y los papeles que el género de referencia asigna respectivamente al emisor y al destinatario (Maingueneau, 2004): entre ellos se establece una cómplice empatía, el redactor abandona el tono didáctico e impersonal y prefiere establecer una relación simétrica con su destinatario, tratando con él de igual a igual. El acercamiento funcional entre los actores implicados no va, obviamente, en detrimento de la autoridad de la voz del emisor, quien tiende a elevar el registro en la quinta sección dedicada a la descripción de los atractivos de la ciudad, recuperando un tono más 'pedagógico' y un estilo más ampuloso, propio del tratado histórico-artístico, vislumbrándose en ciertas ocasiones un estilo más afectado. En la referida sección, por ejemplo, se observa un empleo reiterado de la forma cantase $^{6}$ en lugar de cantara 7 como 'pasado de indicativo', una sustitución forzada y artificiosa que, aunque esté documentada en el uso literario tanto peninsular como americano, "no deja de constituir un rasgo afectado propio de ciertos estilos de lengua, totalmente ajeno a la realidad del funcionamiento del sistema verbal de la lengua viva" (Rojo / Veiga, 1999: 2925). Curiosamente, esta forma verbal aparece sobre todo cuando se señala la autoría, la procedencia o el material del que resulta compuesta una determinada pieza o un monumento:

(4) [Basílica de Nuestra Señora del Pilar]. A medio camino entre la Santa Capilla y el Coro Mayor encontraremos el Altar Mayor de la basílica, con su correspondiente retablo de alabastro que tallase de forma magnífica Damián Forment (GAZ, 75).

(5) [...] Junto a las murallas veremos el Mercado de Lanuza o Mercado Central, construcción modernista que realizase en piedra, hierro y cristal Félix Navarro entre los años 1901 y 1903 (GAZ, 78).

(6) [Iglesia de San Pablo]. En el interior sobresalen el retablo mayor que naciese del cincel de Damián Forment (siglo XVI) (GAZ, 82).

(7) Reparad en el coro, al pie de la nave central, cuyas esculturas dorase José Goya, padre del genial pintor aragonés (GAZ, 82). 
Dicho recurso, ausente en la lengua estándar, tal vez se deba a la necesidad de variatio en la sección descriptiva, en la que los autores intentan rehuir el tono monocorde alternando varias formas verbales de pasado ${ }^{8}$.

Pese a estos melindres estilísticos aislados, el tenor general de la guía sigue la pauta de la informalidad heredada de la Guide Routard y procura crear un terreno común entre los actores de la situación comunicativa. La confianza que se establece de este modo permite al emisor exhibir en la enunciación su propia identidad y su posicionamiento (o ethos discursivo) mediante marcas de primera persona, sin escatimar evaluaciones personales, revalorizando de este modo "la dimensión autobiográfica, experiencial y la mirada subjetiva" y "rechazando la descripción pretendidamente objetiva y científica" (Calvi, 2011: 38), propia de la guía turística convencional (Santulli, 2009a: 91-92).

Entre las marcas que revelan la identidad del emisor, cabe diferenciar las múltiples voces asociadas a la primera persona del plural, que puede desempeñar varias funciones discursivas (Calvi, 2000: 101-105): indicar la autoría colectiva ${ }^{9}$ de la guía; dar a conocer la procedencia geográfica del autor - individual o colectivo - que se revela vecino de Zaragoza y profundo conocedor de la ciudad y de sus tradiciones, autolegitimándose de esta manera en su papel de acompañante de confianza (9); usarse de manera participativa, para implicar tanto al emisor como al destinatario (10). Las proformas de primera persona del singular, en cambio, identifican de manera incontrovertible a un único emisor, que aventura juicios de valor (11):

(8) Sus especulaciones místicas [de Baltasar Gracián] concluyeron en una celda de la Inquisición romana, donde falleció, suponemos - con respeto - que impasible ante la desgracia (GAZ, 39).

(9) Templos Mudéjares. - Con este nombre conocemos en Zaragoza un conjunto de iglesias formado por la de San Gil Abad [...]; Santa María Magdalena [...] y San Miguel de los Navarros [...] (GAZ, 82).

(10) Si bien el centro urbano es fácilmente transitable a pie, Zaragoza nos ofrece un buen servicio de autobuses urbanos que nos permitirán movernos a cualquier punto de la ciudad (GAZ, 102).

(11) [Algunos] estudiosos se distraían así con ejercicios de metafísica aplicada y contribuían a justificar académicamente el cerrilismo de los españoles de antaño - ¿y de ahora? - que mi modesta opinión atribuye tan solo a la ignorancia secular (GAZ, 30).

Como se aprecia en el ejemplo (11), la sinceridad, incluso en las apreciaciones negativas, es la estrategia activada por el emisor para granjearse la confianza del destinatario. Así pues, a pesar de que la sección descriptiva se caracterice en general por su tono eufórico (Dann, 1996: 65, en Calvi, 2011: 38) y por un recurso acusado a un léxico evaluativo-incitativo encaminado a seducir al potencial viajero, no son raros los casos en los que asoman elementos disfóricos (Kerbrat-Orecchioni, 2004: 135-138) o se pronuncian juicios tajantemente negativos. Repárese en los siguientes fragmentos, en los que el emisor pone en tela de juicio la sensatez y el buen gusto de algunas intervenciones urbanísticas, antiguas o contemporáneas $(12,13,14)$ y avisa de algunos aspectos molestos (como las bandadas de palomas que cubren la Plaza del Pilar, amenazando a los turistas con su vuelo rasante) o de la falta de interés de algunos lugares (15), incluso cuando se trata de edificios que fueron marco de acontecimientos históricos solemnes, como el Castillo-Palacio de los Caballeros Hospitalarios, donde en el año 1412 se firmó el Compromiso de Caspe $^{10}$, en la localidad homónima (16). Lo que se desprende es una actitud realista y antirretórica, que va a contrapelo del mito bartesiano de la exaltación del paisaje español en términos pintorescos ${ }^{11}$ :

(12) [Nuevo Barrio de San Bruno] Ubicado frente al ábside de la Seo: un conjunto de 150 viviendas sociales de alquiler, en cuyo subsuelo se han rescatado yacimientos de la ciudad romana [...]. Varios bloques de ladrillo rojo pretenden emular las formas tradicionales de la vivienda zaragozana de épocas pasadas; la torre del reloj que preside el conjunto es un lejano calco de los torreones mudéjares de planta cuadrada del Bajo Aragón. Con independencia del valor social de la obra, el resultado urbanístico - especialmente por su vecindad con la Seo - es más bien dudoso (GAZ, 81).

(13) [Plaza del Pilar] Un proyecto urbanístico caracterizado por su aversión a lo vegetal, como demuestra la actuación en la contigua plaza de la Seo. La estampa de las palomas alfombrando la plaza es ya indisociable de la plaza misma. Cabe prevenir contra sus vuelos rasantes (GAZ, 70 ).

(14) [Basílica de Nuestra Señora del Pilar]. La construcción actual [...] ocupa el mismo emplazamiento que las antiguas iglesias románica y gótica de Santa María la Mayor, ambas demolidas sin piedad (GAZ, 71).

(15) [Iglesia de Santa Engracia]. El interior del templo, fruto de la reconstrucción de 1899 [...] no tiene gran interés (GAZ, 88).

(16) [Caspe. Castillo-Palacio de los Caballeros Hospitalarios]. Se podría decir que apenas son un montón de escombros (GAZ, 194).

Otro elemento textual que realza la subjetividad de algunos enunciados y contribuye a esclarecer el tipo de 'puesta en escena' es el recurso por parte del emisor al "infinitivo enunciativo" (Hernanz, 1999: 2341), inicialmente circunscrito a la lengua hablada del discurso periodístico, pero que hoy se ha extendido también a otras variedades diafásicas, incluso escritas:

(17) Finalmente deciros que Goya trabajó en varios lugares concretos de la Basílica [...] (GAZ, 76).

(18) Como originalidad, deciros que, esta de Zaragoza, fue la primera plaza de toros cubierta de España (GAZ, 88).

La función discursiva desempeñada por esta estructura es "su inscripción en el hic et nunc de la enunciación: posee un claro valor realizativo [...], por cuanto la emisión del infinitivo equivale al acto correspondiente a su denotación” (Hernanz, 1999: 2341). De ahí que enunciados como los de (17) y (18), se refieran forzosamente a una primera persona (la voz de la guía) anclada en el presente 
de la visita, como si, por efecto de un trastrueque temporal, el autor trasladara la enunciación al momento del viaje y estuviese físicamente allí, delante del monumento, escoltando a su público. Al igual que los indicadores de recorrido o los enunciados orientadores ("pasamos bajo..., entramos en..., nos dirigimos a..."), este uso realizativo del infinitivo enunciativo parece más bien propio del itinerario, "que dinamiza las descripciones más estáticas de las guías tradicionales" (Calvi, 2011: 39-40) o de la visita guiada.

La personalización del discurso del emisor ${ }^{12}$ contribuye a construir la correspondiente imagen del lector implicado en la guía (Antelmi, 2010: 38), ya que - recurriendo a una célebre expresión de Lotman (en Lozano, 1999) - el texto "crea a su público a imagen y semejanza" y se configura como intersección de las actitudes y del punto de vista del autor y de su público. Así pues, a la exposición de las marcas deícticas del emisor se corresponde la implicación del interlocutor en el discurso mediante formas de segunda persona del plural (Calvi, 2000: 105-107), particularmente evidentes en las partes más prescriptivas del texto, en las que se recurre a formas imperativas ${ }^{13}$ dirigidas confidencialmente al viajero, a modo de amistosa recomendación (19 y 20), o se anticipan sus futuras reacciones, cuando por fin se encuentre frente al lugar descrito (21):

(19) No paséis por alto el maravilloso trascoro, de estilo renacentista [...] (GAZ, 80).

(20) San Miguel de los Navarros. De traza mudéjar y portada barroca. Reparad en su airosa torre estética (GAZ, 82).

(21) Palacio de los condes de Morata (Audiencia territorial): [...] Os llamará la atención la fachada con decoración en piedra y dos enormes figuras de guerreros [...] (GAZ, 84).

$\mathrm{Si}$ el emisor se revela experto conocedor y vecino de Zaragoza (véase ej. 9), los datos textuales parecen indicar que el lector modelo de la Guía Azul es español y con un nivel cultural elevado, pese a lo que la misma editorial declara en su portal de Internet, donde informa que las Guías Azules "también pueden adquirirse en algunas librerías de Hispanoamérica y Europa" (véase ej. 1). Tal destinatario modelo comparte con el emisor una extensa enciclopedia de conocimientos históricos, artísticos y culturales y es capaz de procesar una amplia gama de significados implícitos, referencias intertextuales, citas y de autor, alusiones, refranes y canciones que - como se verá en el siguiente párrafo - forman parte de la memoria discursiva del viajero de referencia. Entre los numerosos casos, valgan los siguientes tres ejemplos:

(22) Con el tiempo la figura del Justicia habría de convertirse en el símbolo de las libertades nacionales de Aragón. Libertades de las cuales bien orgullosa estaban las Cortes de 1451: "Siempre habemos oído decir antiguamente e se trova por experiencia, que atendida la gran esterilidad de aquesta tierra e pobreza de aqueste Regno, si non fues por las libertades de aquél, se irían a vivir y habitar las gentes a otros Regnos e tierras más fructíferas" (GAZ, 35).
(23) Comprobaréis la idoneidad de estos vinos al degustar algunos de los platos rurales [...] Porque la morcilla que en el asador revienta de Góngora y el vaso de bon vino berceano y campesino, en su unión [...] pueden representar la mejor idea de la hospitalidad concebida por [este] pueblo (GAZ, 63)

(24) Quién no conoce la popular coplilla: "Si vas a Calatayud / pregunta por la Dolores / que es una chica muy guapa / y amiga de hacer favores”... Esta copla ha sido siempre el carné de presentación universal de esta localidad aragonesa (GAZ, 241).

Los contextos anteriores se pueden interpretar como un 'guiño al lector', conocedor de la cultura española (o fuertemente hispanizado), que sabe identificar la fuente intertextual de la cita o tiene suficientes instrumentos culturales para averiguarla, si le despierta curiosidad o algún recuerdo. En los ejemplos (22) y (23) parece evidente el esfuerzo del autor por ennoblecer la descripción del lugar, introduciendo citas y alusiones literarias que el lector experto probablemente sea capaz de reconocer (Santulli, 2009b: 119), mientras que es menos probable que un viajero nacido fuera de la península reconozca los versos de la copla del ejemplo (24). Cabe señalar al respecto que las numerosas citas de autor, estereotipos y clichés de denominación (Margarito, 2000) que contribuyen a configurar la identidad de Zaragoza (p. ej., los títulos que lució a lo largo de su tumultuosa historia cabeza de reino durante la reconquista o la Heróica durante las sublevaciones populares del 1808-1809 - o bien las denominaciones metafóricas de sus alrededores, como "la ribera baja del Ebro, conocida como mar de Aragón" etc. ) representan una convención de género interpretable como estructura iterativa basada en la repetición-reconocimiento de esquemas difundidos recurrentes (Eco 1964: 245-249). Como al niño le resulta agradable volver a escuchar miles de veces el mismo cuento sin variaciones, de igual manera el destinatario de la guía se complace ${ }^{14}$ en volver a encontrar en el texto módulos expresivos, tópicos, alusiones y tics discursivos almacenados en su memoria, que constituyen uno de los fundamentos de la evasión, creando hábitos mentales en la aprehensión de la realidad. Obviamente, el placer de la repetición implica el reconocimiento previo de la estructura iterativa, p. ej., del refrán ("las criadillas rebozadas con leche, huevo y harina [...] gozan de general aceptación, tal vez por aquel refrán que anuncia: de lo que se come se cría" GAZ, 60). En cambio, más trabajosa puede resultarle al viajero común de escolarización medio-baja (tanto español como americano) la interpretación de algunos significados implícitos que se analizan en el párrafo siguiente.

Memoria discursiva, identidad, significados implícitos

Existe un vínculo muy estrecho entre la noción de marco prediscursivo - anteriormente identificada como memoria discursiva (Paveau, 2005), que "elabora, precisándolo, lo que en ámbito pragmático se entiende globalmente por 
contexto" (Antelmi, 2011: 4) - y el concepto de presuposición pragmática definido por Stalnaker (1973, 1974 en Sbisà 1999: 492) como "los presupuestos compartidos por los interlocutores, que constituyen el telón de fondo de su discurso ${ }^{15}$ " "'assumptions shared by the interlocutors, which form the background of their ongoing discourse" trad. mía). A nivel textual, las presuposiciones pragmáticas vienen inducidas por algunos marcadores lingüísticos o activadores (triggers), minuciosamente descritos por Levinson (1983 / 1993) y Sbisà (2007). Abreviando al máximo, según el tipo de activador que la introduce, es posible clasificar la presuposición lingüística en una de las tres siguientes categorías (Portolés, 2007: 131):

- Presuposiciones existenciales - Dependen de unas expresiones referenciales (sintagmas definidos e indefinidos) que dan por sentada la existencia de lo denotado, p. ej., "el tono aragonés es muy peculiar" >> "existe un tono aragonés", que difiere en algo de la entonación del español estándar;

- Presuposiciones léxicas - Activadas por el significado de algunos predicados, como los verbos factivos ${ }^{16}$ (lamentar, asombrar, molestar, descubrir, saber, advertir, darse cuenta, ser consciente etc.); verbos implicativos ${ }^{17}$ (lograr, conseguir, olvidar, evitar, suceder, etc.); verbos de cambio de estado ${ }^{18}$ (descubrir, dejar de, volver, etc.); verbos de juicio ${ }^{19}$ (recriminar, criticar, censurar, etc.); elementos de significado iterativo ${ }^{20}$; comparaciones y contrastes ${ }^{21}$, etc.

- Presuposiciones focales - Activadas por ciertas formulaciones prosódicas o sintácticas. En los textos escritos, se señalan las frases escindidas que destacan un elemento oracional tematizándolo, o los adverbios focalizadores (hasta, incluso, ni siquiera, etc.) que actúan como partículas que evidencian otra unidad lingüística ${ }^{22}$.

La presuposición inducida por dichos activadores puede tener un valor informativo (Sbisà, 1999, 2007) cuando no resulta previamente incluida en las creencias compartidas por los actores. En concreto, la presuposición puede vehicular información totalmente nueva para el destinatario, quien tendrá que 'acomodar' el contenido presupuesto por el emisor, agregándolo al conjunto de los conocimientos compartidos. En este caso, el uso de activadores presuposicionales permite compactar la información para agilizar la exposición, sin tener que proporcionar informaciones prolijas; el destinatario que no esté al corriente de algún dato presupuesto tendrá simplemente que 'acomodarlo' al telón de fondo del discurso:

(25) Goya pintó varios óleos para la Cartuja de Aula Dei, el año 1774. Cuatro de estas obras se perdieron tras la desamortización, pero siete piezas originales [...] se pueden ver y admirar en las paredes de la iglesia (GAZ, 89-90).

En este contexto, la expresión referencial la desamortización activa una presuposición de existencia y de unicidad ("se produjo una desamortización concreta, después del año 1774"), que sin embargo no tiene por qué formar parte necesariamente del saber enciclopédico del destinatario, ya que ningún elemento del cotexto inmediato ${ }^{23}$ permite recuperar la información de que las citadas obras de Goya se hallasen en algún momento 'en poder de manos muertas' y por qué razón. Semejante uso de la presuposición, que apela a la memoria histórica colectiva de un público culto, constituye un recurso económico mediante el cual el emisor se ahorra soporíferas digresiones académicas, sin mermar la función 'informadora' del texto.

Cuando, sin embargo, lo que se presupone tiene que ver con valores como la identidad, la religión, los modelos de organización social o las visiones del mundo propias de un agente específico, entonces la presuposición puede desempeñar, incluso en la guía turística, una función no solo informativa sino también persuasiva (Sbisà, 2007: 90), contribuyendo a forjar una determinada identidad del lugar (la que se tiene interés en fomentar) y añadiendo piezas a la memoria discursiva de los destinatarios. Se trata de una operación ideológica nada inocente, ya que obliga al lector a ver una determinada imagen de la ciudad, según el baremo de evaluación del emisor. De hecho, un contenido introducido solapadamente como presupuesto no requiere la adhesión explícita y consciente del destinatario, sino que se 'impone' en el marco prediscursivo y se agrega automáticamente al trasfondo del intercambio, convirtiéndose en una verdad incontrovertible. Las evidencias textuales observadas en la GAZ demuestran que las presuposiciones informativo-persuasivas - junto con los demás significados implícitos como las implicaturas conversacionales y la ironía - subvierten los mitos burgueses del nacionalismo y del catolicismo que connotaban la Guide Bleu de bartesiana memoria y atestiguan en cambio el fuerte arraigo de los nuevos mitos del localismo y del laicismo, propios de amplios sectores de la sociedad española contemporánea. Asimismo, para la identificación del carácter de la ciudad, el componente humano parece jugar un papel determinante en el plano discursivo, a diferencia de lo que Barthes notó en la edición francesa de la guía que nos ocupa. Concentrando el análisis en la sección información general, que por su carácter argumentativo y ensayístico deja entrever el posicionamiento ideológico del autor, se aprecia de entrada la confutación del mito de la prístina nobleza y del esplendor cultural de los primeros habitantes del solar aragonés, que constituye un cliché de muchas guías de países mediterráneos (p. ej., de la isla de Chipre, véase Kerbrat-Orecchioni, 2004). Los actos veredictivos que se observan en los fragmentos siguientes no dejan dudas acerca de la actitud crítica y para nada celebradora del autor al respecto:

(26) Vascones, iacetanos, suessetanos, ilergetes, ilercavones, sedetanos, titos, belos, lusones, turboletas, lobetanos. Tales fueron las tribus que poblaron el solar aragonés antes de la instauración del poder romano. Muchos y mal avenidos. Pueblos pastoriles y belicosos, de los cuales dice Estrabón que andaban siempre a la greña unos contra otros. Algunos historiadores - por ejemplo Sánchez Albornoz - olvidaron el fundamento científico de su disciplina y cuatro nociones nada superfluas de economía y sociología para decla- 
rar que, del individualismo aguerrido de estas tribus pervive cierto "talante secular de los pueblos hispanos", patente aún en nuestros días: tales estudiosos se distraían así con ejercicios de metafísica aplicada y contribuían a justificar académicamente el cerrilismo de los españoles de antaño - ¿y de ahora? - que mi modesta opinión atribuye tan solo a la ignorancia secular. El caso es que los antiguos habitantes de Iberia combatían por igual a los romanos y a sus vecinos [...] (GAZ, 30).

La condición de éxito de los actos veredictivos contenidos en este ejemplo prevé que el emisor sea competente para pronunciarse con imparcialidad sobre temas históri$\cos$ y que posea criterios de juicio fiables. La presuposición asociada a estos enunciados, por lo tanto, es que el autor dice la verdad y está en lo justo, lo cual le permite imponer su lectura de la historia entre los presupuestos prediscursivos del destinatario como dato incontestable. Obsérvese, además, el modulador mi modesta opinión que no solo expone la imagen de un emisor irónico, sino que sirve para suavizar de alguna manera sus invectivas contra los historiadores que preconizaban una lectura ennoblecedora del pasado prerromano aragonés, donde los incondicionales del españolismo pretenden encontrar los gérmenes de un hipotético talante bravío de los pueblos hispanos. El autor no duda en tildar de "ignorancia secular" esta visión dignificadora de las tribus que poblaron originariamente la comarca zaragozana y para apuntalar su ethos discursivo esgrime un argumentum ad auctoritatem, citando al geógrafo e historiador griego Estrabón. Tal interpretación - necesariamente sesgada e ideológica - es funcional para los propósitos discursivos de la guía: derribar los tópicos del nacionalismo español más rancio (una sola nación, católica y de ilustres orígenes, talante bravo de los españoles) para afirmar los mitos del localismo nacional (nobleza de las antiguas leyes de Aragón, temperamento democrático y solidario de sus habitantes, belleza de su entorno natural, exquisitez de su cocina, etc.). Los romanos, por supuesto, civilizaron Aragón, poblada a la sazón por gente ruda pero ya versada en los negocios (este sí un rasgo positivo heredado por los actuales aragoneses). En el ejemplo siguiente, la presuposición de existencia activada por las descripciones definidas y por la estructura concesiva ${ }^{24}$ desempeñan una evidente función informativo-persuasiva, dirigida a presentar una determinada visión de los colonizadores y de los colonizados como dato indiscutible. Entre dichas descripciones, destaca la expresión referencial aquellos salvajes no tan buenos, que establece una comparación irónica entre los antiguos habitantes de Aragón y el topos del buen salvaje de Rousseau, almacenado en la memoria histórica del lector:

(27) Pese a la tenaz resistencia opuesta contra el invasor, pudo más la organización romana que el caos ibérico. Bajo el estandarte del SPQR llegaron las humanidades, las obras públicas y un acelerado proceso de urbanización del Valle del Ebro. No así la moneda que aquellos salvajes no tan buenos ya empleaban (GAZ, $30)$.

Pese a la romanización, la imagen de los antiguos habitantes de Zaragoza y de su monarquía no sale bien parada de la narración selectiva de las efemérides históricas posteriores. $\mathrm{Al}$ aludir a la invasión árabe de la comarca, el autor se regodea en referir una anécdota que mortifica la secular pujanza de los pueblos hispanos, evocada por Sánchez Albornoz en el ejemplo de (26), mofándose también de la opinión de los historiadores clásicos, quienes intentaron enmascarar de patriotismo los auténticos picores del rey don Rodrigo de Aragón (28). También en este caso, las condiciones de éxito de los actos indirectamente veredictivos presuponen la fiabilidad del autor, quien se complace en enfatizar el oportunismo y la cobardía de los zaragozanos de antaño, generalizando esa conducta (expresada mediante el verbo de cambio chaquetear) hasta considerarla práctica común de los españoles contemporáneos, recurriendo a una comparación ideológicamente sesgada, fundada en el antiguo tópico nihil novo sub sole:

(28) La invasión agarena tomó por sorpresa al rey don Rodrigo mientras folgaba con la hija del conde don Julián [...] - según los historiadores, estaba guerreando contra los indómitos vascones - y alcanzó las murallas cesaraugustanas el año 714. Cuentan que la ciudad no opuso excesiva resistencia a las fuerzas del Islam, como vino a ocurrir en la práctica totalidad del hoy denominado territorio nacional. Cambio de poder y cambio de nombre: donde antes ponía Avenida del Generalísimo hoy pone Avenida de la Constitución, lo antes se llamaba Caesaraugusta pasó a conocerse por Saraqustat. La población chaqueteó en su inmensa mayoría, adoptando el islam. (GAZ, 32).

Cabe destacar que en la reconstrucción histórica del autor - apenas mitigada por un modulador evidencial (cuentan que) - el mito fundador de la identidad local empieza a forjarse a partir de la creación del primer núcleo estatal aragonés, gracias a los héroes que se sustrajeron a la dominación agarena. Ese 'prístino' embrión político fue la cuna de la lengua aragonesa, otro factor de identidad cuya pérdida, debida a la penetración de la lengua del imperio, el autor lamenta reiteradamente:

(29) Los más irreductibles emigraron al Pirineo [...] donde aparecerá el prístino Condado de Aragón, que debe su nombre al río homónimo y en cuyo territorio se forjó la lengua romance aragonesa, hoy apenas conocida [negrita en el texto] (GAZ, 33).

(30) La historia demostrará que su acceso al trono [de los Trastámaras] sería perjudicial para los intereses de Aragón. Empezando por el debilitamiento y la discriminación de la lengua aragonesa, marginada por una nueva administración castellanizada (GAZ, 36).

Informa el autor que las desgracias para la supervivencia de la identidad aragonesa empiezan a perfilarse con el compromiso de Caspe (1412) y con el ascenso al trono de la dinastía de los Trastámaras, cuyos soberanos se dejarían colonizar culturalmente por la vecina Castilla. 
Nótense en (30) el uso de los sustantivos determinados debilitamiento y discriminación, derivados de los verbos de cambio de estado debilitar y discriminar que, como marginar, presuponen una situación anterior más favorable y añorada. Así pues, la dicotomía irreconciliable entre centralismo y localismo político connota toda la narración de los avatares históricos en la GAZ, desde la época imperial hasta nuestros días, con un evidente posicionamiento de la voz narrante a favor de los autonomistas aragoneses antiguos y contemporáneos:

(31) En el imperio de los Austrias no se ponía el sol, pero sobre Aragón planeaban las brumas de la bancarrota de la hacienda pública, el hambre y las epidemias (GAZ, 36).

(32) Las Cortes de Tarazona de junio de 1592 recortarían los privilegios aragoneses, hasta reducirlos a niveles casi simbólicos para incrementar el poder real, especialmente en su jurisdicción legal y económica (GAZ, 37).

(33) Los partidos republicanos y de izquierda redactan en mayo de 1936 un proyecto de estatuto de autonomía, el Estatuto de Caspe, a semejanza de los estatutos vasco y catalán. [...] La sublevación militar de junio de 1936 da al traste con los renovados sueños de libertad aragoneses (GAZ, 44).

(34) La postrera jugarreta del franquismo al pueblo aragonés consistió en el proyecto de trasvase de las aguas del río Ebro a Cataluña, con el subsiguiente peligro para la integridad de los regadios aragoneses. Corría el año 1973 y más de 250.000 firmas contra el trasvase lograron reunirse en Aragón, pudiéndose frenar con esta presión social la arbitrariedad del gobierno central (GAZ, 46).

(35) Muerto Franco, los aragoneses han dado cumplidas muestras de su talante democrático y firme voluntad de autogobierno [...] Cien mil personas habían pedido la autonomía de Zaragoza el año 1978 [...]. La lucha pacífica y democrática por la mayor profundización de las competencias autonómicas sigue viva entre los aragoneses. Más de 130.000 personas se manifestaron con este motivo en Zaragoza en el mes de abril de 1992. Unos cuantos miles se desplazaron hasta Madrid para efectuar allí idéntica reivindicación en noviembre del mismo año, desplegando una inmensa bandera cuatribarrada frente al Congreso de los Diputados en Madrid (GAZ, 46).

Todos los contextos anteriormente indicados expresan juicios de valor cuanto menos personales más que evidencias científicas objetivas, es probable que otra guía presentaría un esbozo histórico de Zaragoza bajo un sesgo ideológico diferente. Es el recurso a presuposiciones persuasivas lo que convierte la lectura 'filoaragonesa' de los acontecimientos en 'información de fondo' irrefutable, accionando un repertorio de mitos opuestos a los del españolismo, que sin embargo dejan evidentes huellas textuales. En los fragmentos 31-35, por ejemplo, activan presuposiciones persuasivas las descripciones definidas (las brumas de la bancarrota de la hacienda pública, el hambre y las epidemias; los privilegios aragoneses, los renovados sueños de libertad aragoneses, peligro para la integridad de los regadios aragoneses, etc.), los verbos de cambio de estado (recortar, reducir, incrementar, dar al traste, frenar), los verbos de valor implicativo (lograr) o los actos lingüísticos que expresan influencia y reclamación ( $m a$ nifestarse, reivindicar, con sus respectivos sustantivos deverbales), cuyas condiciones de éxito entrañan que el emisor ha visto vulnerados sus derechos legítimos (Sbisà, 2007: 66; Escribano, 2009: 26).

El complemento natural de la retórica antiespañolista de la GAZ es la actitud anticatólica manifestada por sus autores, quienes describen con sorna irreverente la evangelización de Iberia, buscando la complicidad de un lector laico, capaz de reírse de los pasados desmanes religiosos de su país:

(36) Y fue en tiempos de la paz romana cuando un oscuro hijo de Israel llamado Iago - o Santiago para entendernos - arribó a Iberia para relatar cierta buena nueva a sus tercos pobladores. Al menos eso dice la leyenda [...]. Más probable parece la hipótesis de la llegada de algún converso [...] al que se encomendó la evangelización de este extremo - hasta hace poco se le denominaba trasero - de Europa. Pero la católica España no podía conformarse con la triste posibilidad de haber recibido el cristianismo de algún discípulo anónimo de los apóstoles de Jesús. No, ipor favor!, tuvo que ser uno de los doce y el más farruco $y$ militaroide de todos, Santiago Matamoros, quien evangelizó al Faro de Occidente. Y puesto que Jesús ya había ascendido a los cielos, vino en persona la Virgen María para ratificarlo en tan santa empresa y reconfortar su ánimo atribulado por la cazurrería de los iberos, apareciéndose sobre un pilar a la orilla del Ebro en la noche del 2 de enero del año 40 D.C. (GAZ, 31).

El ejemplo (36) constituye un enunciado irónico que vehicula un significado implícito interpretable como mención ecoica: no recurre solo a mecanismos presuposicionales (como las descripciones definidas, p. ej. sus tercos pobladores, la cazurrería de los iberos), sino que implica la mención o repetición de una opinión contraria considerada inadecuada (Ruiz Gurillo, 2006: 121-135). En este caso, el blanco de la burla desacralizadora son los tópicos de la tradición católica española, con su altisonancia aliada de los antiguos delirios imperialistas (No, ipor favor!, tuvo que ser uno de los doce y el más farruco y militaroide de todos, Santiago Matamoros, quien evangelizó al Faro de Occidente), que se dan de bruces con la presupuesta ignorancia de los iberos y con lo que fue el papel real de España en el mundo según el autor (hasta hace poco trasero de Europa). Este uso interpretativo del lenguaje es posible gracias al entorno cognitivo compartido (que da por sentada una sensibilidad laica) y gracias al rasgo coloquializador de la relación vivencial de proximidad (Briz, 1996: 31), mediante el cual el emisor procura involucrar a su destinatario (§ 2). La evocación de la opinión contraria representa, por tanto, un estímulo altamente ostensi- 
vo para el lector, quien interpreta el implícito apelando a la presunción óptima de relevancia del enunciado en su contexto discursivo (Sperber / Wilson, 1978). Desde la vertiente de la teoría de la polifonía (Ducrot et alii, 1980, Ducrot 1986), el locutor presenta aquí su enunciación como la expresión de un punto de vista de un enunciador E del cual se distancia, de manera que el locutor se responsabiliza de la enunciación, pero no de la voz de la tradición católica, objeto de mofa. La actitud de los autores frente al catolicismo se refleja también en la sección descriptiva de la guía, dedicada a la visita, donde prevalece un tono impersonal de falsa objetividad (Santulli, 2009b: 116-119), caracterizado por un uso partidario de la adjetivación. En general, en la descripción de los monumentos de la cristiandad prevalece un vocabulario axiológico positivo (Kerbrat-Orecchioni, 2004: 140-143) que exalta la calidad artística y el tamaño de las piezas:

(37) Sobre el Altar Mayor y acrecentando la grandiosidad del conjunto se contempla la cúpula central de la basílica, decorada al fresco [...] (GAZ, 76)

(38) El retablo del Altar Mayor es un impresionante conjunto de alabastro labrado en proporciones mastodónticas [...] (GAZ, 79).

No obstante, no son nada raros los adjetivos implícitamente negativos que reflejan un punto de vista crítico acerca de los excesos del arte barroco, entre los cuales destaca, en orden de frecuencia, abigarrado. Los autores focalizan su juicio estético en el derroche de elementos embriagadores para la vista, que aparecen tematizados, relegando en segundo plano el efecto de compensación axiológica:

(39) Iglesia de San Carlos Borromeo [...]. Encierra un delirio de imágenes, escorzos, volutas, oropeles, columnas salomónicas ... todo ello tremendamente abigarrado. La vista se extravía entre tanto ornamento. Una "barroquísima exageración", pero sin duda bella y de trabajosa factura (GAZ, 88).

Otro adjetivo que entraña un juicio intrínsecamente negativo es grandilocuente:

(40) Catedral del Salvador (La Seo) [...] El conjunto es de proporciones mucho menores a la grandilocuente Basílica del Pilar, aun siendo mayor su riqueza estilística (GAZ, 79).

Asimismo, al mencionar las numerosas tradiciones relacionadas con el culto de la 'Pilarica', la actitud del emisor no manifiesta ninguna implicación emotiva. De esta manera, el autor asume el papel de antropólogo, quien se limita a observar datos etnográficos desde una perspectiva externa, aunque al final no renuncie a introducir formas evaluadoras, p. ej., el adjetivo peculiar:

(41) Otra [tradición] es el beso al "pilar" que, en realidad, no es un pilar sino una columna sobre la que se apareció la Virgen y que ha permanecido en el mismo lugar desde aquella legendaria madrugada. Un fragmento de la columna puede verse y besarse a través de un pequeño ventanuco [...] Gentes de todas las edades, sexo y condición acuden a depositar un beso sobre tan peculiar objeto de culto (GAZ, 74).
Dicha actitud ante la tradición católica explica por qué los autores, aun reconociendo el inestimable valor artísticos de los monumentos religiosos zaragozanos, no se extienden nunca en recomendaciones y dejan al destinatario la elección de detenerse o no delante de una pieza: (42) [Retablo del altar mayor de la basílica]. Una delicia para los amantes de la escultura, también para aquellos que tengan tiempo y ganas de escudriñar las escenas esculpidas para averiguar su sentido (GAZ, 76).

\section{Conclusiones}

La Guía Azul de la editorial Gaesa, heredera de la tradición y del prestigio cultural del Guide Bleu de Hachette, se configura como producto híbrido, a medio camino entre la guía culta y la guía práctica. Los mecanismos lingüísticos que actúan en el texto contribuyen a configurar la 'escena de enunciación' (Maingueneau, 2007), es decir, el mundo que se define mediante el acto enunciativo, que se concretiza en la imagen de Zaragoza ofrecida por los autores. Analizando el posicionamiento de los actores implicados en la enunciación (o escenografía), se entrevé la identidad discursiva del autor colectivo, quien renuncia al tono didáctico e impersonal para tejer una relación empática y simétrica con su lector modelo, un visitador joven, dinámico e informado, de cultura laica y capaz de confeccionar su itinerario en autonomía.

La identidad zaragozana que surge de tal puesta en escena se negocia en el texto durante la interacción y estriba en la memoria discursiva compartida (Paveau, 2005), a saber, en marcos prediscursivos colectivos - conocimientos enciclopédicos, creencias y mitos - propios de la cultura española. El análisis realizado, además de comprobar una atenuación del propósito didáctico y procedural de la guía en cuestión, ha puesto de relieve la íntima relación entre la memoria discursiva y algunas formas de la comunicación implícita, como las presuposiciones informativas usadas con una finalidad persuasiva (Sbisà, 2007) y los enunciados irónicos, interpretables como casos de mención ecoica de enunciados previos (Sperber / Wilson, 1978), de los que el emisor pretende distanciarse. Las evidencias textuales permiten destacar una clara evolución en el repertorio de mitos que sustentan el andamiaje ideológico de la Guía Azul desde 1957, fecha en la que Barthes publicó su famoso ensayo, hasta nuestros días. De hecho, los aspectos pintorescos del paisaje español y la celebración del espacio arquitectónico ocupado solo por los monumentos de la cristiandad - totalmente al margen de su geografía humana - ceden la escena a una visión laica y localista del territorio, poblaba por los mitos del autogobierno y por el síndrome de la 'periferia' históricamente vejada por el poder central. En este nuevo sistema de significación, el componente humano asume un papel más central y la tradición cristiana se convierte en el blanco de críticas indirectas, cuando no de auténtico escarnio. 


\section{Bibliografía}

Antelmi, Donatella

2010 "Viaggiatori e testi: identità discorsive". E/C Serie Speciale, Anno IV (6): 35-42.

Antelmi, Donatella

2011 "Guías turísticas, intertextualidad y memoria discursiva: las Guías de Italia en lengua francesa”. En Calvi, Maria Vittoria / Mapelli, Giovanna (Eds.), La lengua del turismo. Géneros discursivos y terminología (pp. 75-92). Bern: Peter Lang.

Barthes, Roland

1957 / 1999 Mitologías, México DF: Siglo XXI (original: Mythologies. Paris: Seuil)

Briz, Antonio

1996 El español coloquial: Situación y uso. Madrid: Arco / Libros.

Calvi, Maria Vittoria

2000 Il linguaggio spagnolo del turismo. Viareggio-Lucca: Mauro Baroni.

Calvi, Maria Vittoria

2011 "Pautas de análisis para los géneros del turismo". En Calvi, Maria Vittoria / Mapelli, Giovanna (Eds.), La lengua del turismo. Géneros discursivos y terminologia (pp. 19-45). Bern: Peter Lang.

Ducrot, Oswald et alii

1980 Les mots du discours. Paris: Minuit.

Ducrot, Oswald

1986 El decir y lo dicho. Polifonía de la enunciación. Barcelona: Paidós.

Eco, Umberto

1964 Apocalittici e Integrati. Milano: Bompiani.

Eco, Umberto

1979 Lector in fabula. Milano: Bompiani.

Escribano, Asunción

2009 Las voces del texto como recurso persuasivo. Madrid: Arco / Libros.

Fairclough, Norman

1995 Critical Discourse Analysis : the Critical Study of Language. London: Longman.

Foucault, Michel

1969 L'archéologie du savoir. Paris: Gallimard

Hernanz, Lluïsa

1999 "El infinitivo". En Bosque, Ignacio / Demonte, Violeta (Eds.), Gramática Descriptiva de la Lengua Española, vol. 2 (pp. 2197-2356). Madrid: Espasa.

Kerbrat-Orecchioni, Catherine

2004 "Suivez le guide! Les modalités de l'invitation au voyage dans les guides touristiques: l'exemple de l'«île d'Aphrodite»". En Baider, Fabienne / Burger, Marcel; Goutsos, Dionysis (Eds.), La Communication Touristique. Approches discursives de l'identité et de l'altérité (pp. 131-150). Paris: L'Harmattan.

Kiparsky, Paul; Kiparsky, Carol

1971 "Fact". En Steinberg, Danny / Jakobovits, Leon (Eds.), Semantics : An Interdisciplinary Reader in Philosophy, Linguistics and Psychology (pp. 345-369). Cambridge: Cambridge University Press.
Levinson, Stephen, C.

1983 / 1993 La Pragmatica. Bologna: Il Mulino (original: Pragmatics. Cambridge: Cambridge University Press). Lozano, Jorge

1999 "Cultura y explosión en la obra de Yuri M. Lotman", Espéculo. Revista de estudios literarios. Madrid: Universidad Complutense de Madrid, http://www.ucm.es/ info/especulo/numero11/lotman2.html

Maingueneau, Dominique

2004 Le discours littéraire. Paratopie et scènes d'énonciation. Paris : Colin.

Mapelli, Giovanna / Piccioni, Sara

2011 "Taxonomía de los textos turísticos: factores lingüísticos y factores contextuales". En Calvi, Maria Vittoria / Mapelli, Giovanna (Eds.), La lengua del turismo. Géneros discursivos y terminología (pp. 47-73). Bern: Peter Lang.

Mapelli, Giovanna / Santos López, Javier

2010 "Estudio comparado de las características discursivas de la guía turística". En Canals, Jordi / Liverani, Elena (Eds.) Viaggiare con la parola (pp. 89-102). Milano: FrancoAngeli

Margarito, Mariagrazia

2000 "La bella Italia des guides touristiques: quelques formes de stéreotypes". En Margarito, Mariagrazia (Ed.), L'Italie en Stéréotypes. Analyse de textes touristiques (pp. 9-36). Paris : L'Harmattan.

Moirand, Sophie

2004 "Le même et l'autre dans les guides de voyage au $\mathrm{XXI}^{\mathrm{e}}$ siècle". En Baider, Fabienne / Burger, Marcel; Goutsos, Dionysis (Eds.), La Communication Touristique. Approches discursives de l'identité et de l'altérité (pp. 151-172). Paris: L'Harmattan.

Montolío, Estrella

2001 Conectores de la lengua escrita. Barcelona: Ariel.

Paveau, Anne-Marie

2005 "Retrouver la mémoire. Parcours épistémologiques et historiques" Colloque SEAD II (II Seminário de Estudos em Análise do Discurso Porto Alegre). Porto Alegre, 30 oct.-4 nov. <http://www.discurso.ufrgs.br/ sead/simposios.html>.

Portolés, José

2007 Pragmática para hispanistas. Madrid: Síntesis.

Real Academia Española (RAE) / Asociación de las Academias de la Lengua Española

2010 Nueva Gramática de la Lengua Española. Manual. Madrid: Espasa.

Rojo, Guillermo / Veiga, Alexandre

2009 "El tiempo verbal. Los tiempos simples". En Bosque, Ignacio / Demonte, Violeta (Eds.), Gramática Descriptiva de la Lengua Española, vol. 2 (pp. 2935-2975). Madrid: Espasa.

Ruiz Gurillo, Leonor

2006 Hechos pragmáticos del español. Alicante: Universidad de Alicante.

Santulli, Francesca

2009a "La Guida Breve della Consociazione Turistica Ita- 
liana (1939)". En Santulli, Francesca / Antelmi, Donatella / Held, Gudrun (Eds.), Pragmatica della comunicazione turistica (pp. 90-105). Roma: Editori Riuniti University Press.

Santulli, Francesca

2009b "La Guida Rapida d'Italia del Touring Club Italiano (nuova edizione 1994)". En Santulli, Francesca / Antelmi, Donatella / Held, Gudrun (Eds.), Pragmatica della comunicazione turistica (pp. 106-119). Roma: Editori Riuniti University Press.

Sbisà, Marina

1999 "Ideology and the Persuasive Use of Presupposition". En Verschueren, Jef (Ed.), Language and Ideology. Selected Papers from the $6^{\text {th }}$ International Pragmatics Conference, vol. 1. (pp. 492-509). Antwerp: International Pragmatics Association.

Sbisà, Marina

2007 Detto e non detto. Le forme della comunicazione implicita. Roma-Bari: Laterza.

Sperber, Dan / Wilson, Deirde

1978 "Les ironies comme mentions", Poétique, 36 : 399412.

VV. AA.

2008 / 09 Guía Azul Zaragoza. Madrid: Gaesa.

\section{Notas}

1 De ahora en adelante, la cursiva en los ejemplos es mía, mientras que la negrita figura siempre en el original.

2 Información tomada del portal Wikipedia, en la dirección http: //es.wikipedia.org/wiki/Grupo_Anaya (12/11/2011).

3 No parece una coincidencia que la dirección internet de 'Guías Azules de España' sea www.guiazuldeltrotamundos.es

4 La conocida oposición antinómica entre turista - identificado con el denostado turista de masas - y viajero - protagonista activo y autónomo de la experiencia del viaje - (Calvi, 2011: 11) ha sido sometida recientemente a una revisión que ha difuminado las fronteras entre los dos conceptos. Al parecer, en este ámbito discursivo el término turista se va despojando de las connotaciones negativas que constituyen una herencia decimonónica y se carga de otros matices diferenciadores que, por adjetivación, atribuyen nuevos rasgos positivos y diversifican la identidad del turista en infinitas tipologías, como "turista responsable" o "turista concienzudo" (Antelmi, 2010: 41; Calvi, 2011: 12).

5 El concepto de 'escenografía' empleado aquí fue desarrollado por Dominique Maingueneau, quien lo definió como 'puesta en escena de la enunciación' que justifica y legitima la inserción del autor en la narración literaria (véase Maingueneau, 2004 : 70-223).

6 Siguiendo la tradición gramatical (véase RAE 2010: 428), se usa el verbo cantar a modo de comodín para identificar fácil- mente el tiempo verbal, distinguiendo las formas del pretérito imperfecto de subjuntivo en - ara y en - asel-ese.

7 El empleo del pretérito imperfecto de subjuntivo en - ara como tiempo pasado de indicativo (sobre todo como pluscuamperfecto de indicativo) se debe al valor etimológico de cantara (< lat. cantaveram, 'pluscuamperfecto de indicativo') y sigue siendo característico del español peninsular noroccidental, conservándose, p. ej., en el sistema verbal del gallego. Véanse Rojo y Veiga (1999: 2924-2927) para mayor profundización en esta alternancia y en algunos usos marginales de formas verbales simples.

8 De hecho, la forma cantara alterna con cantase - aunque con menor frecuencia - en contextos parecidos de la mencionada sección, p. ej.: "[Plaza de los Sitios] Está presidida por el Monumento a los Sitios que realizara en 1908 Augustín Querol", "La estatua del emperador Augusto [...] es una copia en bronce del original que en 1940 regalara Mussolini a la ciudad de Zaragoza" (GAZ, 86 y 77).

9 Según se indica en la portada interna de la guía que nos ocupa, el texto fue escrito por un grupo de redactores formado por Paloma Legrado Villafuertes, Ignacio González Orozco, Isabel Aizpún, Enrique Yuste del Real. No se especifica, sin embargo, cuáles secciones fueron redactadas por quién.

10 Acuerdo establecido en 1412 por representantes de los reinos de Aragón, Valencia y el principado de Cataluña para elegir un nuevo rey, tras la muerte en 1410 de Martín I de Aragón, quien no dejó descendientes ni a un sucesor designado. Supuso la entronización de Fernando de Trastámara en la Corona de Aragón.

11 En contextos eminentemente disfóricos, no faltan (aunque no pueda decirse que abunden) los casos de compensación axiológica del negativo al positivo (Kerbrat-Orecchioni, 2004: 144), que suelen ir introducidos por un conector contrargumentativo (Montolío, 2001), p. ej.: "Un problema destacable en algunas zonas como es el casco antiguo es el tráfico que impide un paseo sosegado y atento. Pero no hay que desanimarse en absoluto por ello. Ni el tráfico, ni los "delirios" posmodernos privan a Zaragoza de su riqueza y variedad monumental y artística [...]" (GAZ, 53).

12 A este respecto, véanse también los estudios de Mapelli/Piccioni (2011) y de Mapelli/Santos 2010 que profundizan en la mayor personalización del discurso en las guías contemporáneas usadas por los viajeros, que se apartan del modelo de la descripción impersonal de las guías tradicionales (Santulli, 2009a: 104-105).

13 En los ejemplos que se ofrecen no se produce el así llamado desembrague (débrayage) actancial que sí se realiza cuando se seleccionan actos directivos con formulación impersonal, que no implican directamente al destinatario. Dicho desembrague, característico de la guía tradicional, desempeña una función 
pragmática, ya que esconde la finalidad pedagógica-impositiva de la guía, relegándola a un segundo plano (Santulli, 2009a: 104).

14 Desde la perspectiva epistemológica preconizada por Eco (1979), el destinatario más ingenuo de la guía reacciona como el típico lector modelo de primer nivel. Este goza del texto en cuanto dispositivo semántico y es víctima de las estrategias del autor, quien lo va conduciendo a lo largo de una serie de expectativas y previsiones. El viajero más avisado, en cambio, recibe el texto como lector crítico de segundo nivel, siendo capaz de disfrutar de los mecanismos seriales y de apreciar las eventuales variaciones.

15 Como se sabe, estos presupuestos de fondo, compartidos por los hablantes, se dan por sentados y no son cancelables por definición. Por este motivo, la presuposición permanece aunque se niegue el enunciado en el que aparece: Juan ha dejado de fumar $>>$ Juan fumaba; Juan no ha dejado de fumar $>>$ Juan fuma. La no cancelabilidad de las presuposiciones se debe al hecho de que son implicaturas convencionales y no conversacionales (Portolés, 2007: 130).

16 Presuponen la verdad de lo representado en la subordinada que rigen, p. ej., "sintió mucho marcharse" >> "se marchó" (Kiparsky / Kiparsky, 1971; Sbisà, 2007: 81).

17 Introducen una implicación lógico-pragmática acerca de la subordinada que rigen (Karttunen, 1971 citado en Levison, 1983/1993: 188). Se diferencian en: 1) implicativos del tipo A (lograr, conseguir, etc.), que presuponen que la subordinada es verdadera si dichos verbos son afirmados y falsa si son negados (logró/ consiguió llegar a tiempo >> llegó a tiempo; no logról no consiguió llegar a tiempo $>>$ no llegó a tiempo); 2) implicativos de tipo B (evitar, impedir, etc.) que representan la situación opuesta: suponen la verdad de la subordinada si son negados y al revés (no evitó / impidió que su marido se fuera de casa >> su marido se fue de casa; evitó / impidió que su marido se fuera de casa $>>$ su marido no se fue de casa).

18 Presuponen la existencia de un estado anterior diferente, en el cual no se realizaba lo que predica la subordinada (Sellers, 1954 y Karttunen, 1973 citados en Levinson, 1983/1993: 189).

19 Presuponen que el hablante satisface las condiciones de éxito del acto veredictivo que dichos verbos realizan, a saber, que es competente con respecto de lo que juzga y que su criterio de juicio es justo y verdadero (Fillmore, 1971 citado en Levinson, 1983/1993: 189; Sbisà, 2007: 65-66).

20 Presuponen la repetición de algo que se ha producido también anteriormente (Sbisà, 2007: 69-70).

21 Las comparaciones y los contrastes incluyen también el caso del superlativo relativo, sumamente presente en los textos turísticos, que presupone la existencia de una pluralidad de objetos, comparables según una propiedad determinada (Lakoff, 1971 citado en Levinson, 1983/1993: 190-191; Sbisà, 2007: 79).

22 Tanto las frases escindidas como los elementos focalizadores activan presuposiciones cuyos elementos léxicos aparecen en la superficie del texto, aunque no como enunciados completos. Es necesario un mínimo de restructuración para explicitarlas, p. ej., Fueron los Aragoneses quienes se llevaron la victoria >> Alguien se llevó la victoria.

23 La guía explica en qué consistió la desamortización de los bienes eclesiásticos treinta y nueve páginas antes del contexto indicado. Por razones de economía, la sección descriptiva presupone que el lector comparte esa información histórica esencial. En realidad, sin embargo, el turista común realiza una lectura selectiva del texto y no procesa fácilmente la información que no esté inmediatamente disponible en el cotexto.

24 Con respecto a las subordinadas concesivas, "se puede considerar como presupuesto el contenido de todas aquellas que no implican hipótesis contrafácticas claramente reconocibles como tales" (Sbisà, 2007: 83).

Recibido:

$8 / 1 / 2012$

Reenviado:

$16 / 2 / 2012$

Aceptado: $20 / 2 / 2012$

Sometido a evaluación por pares anónimos 